NASA Technical Memorandum 106581

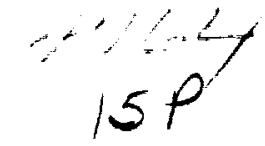

\title{
An Interactive, Design and Educational Tool for Supersonic External-Compression Inlets
}

Thomas J. Benson

Lewis Research Center

Cleveland, Ohio

Prepared for the

30th Joint Propulsion Conference

Cosponsored by the AIAA, ASME, SAE, and ASEE

Indianapolis, Indiana, June 27-29, 1994

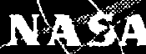

National Aeronautics and Space Administration

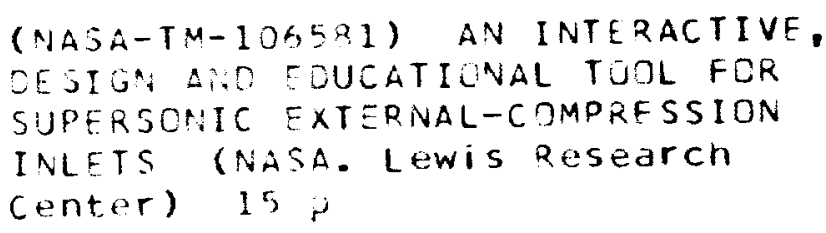




\title{
An Interactive, Design and Educational Tool for Supersonic External-Compression Inlets
}

\author{
Thomas J. Benson* \\ NASA Lewis Research Center \\ Cleveland, Ohio 44135
}

March 29, 1994

\begin{abstract}
A workstation-based interactive design tool called VU-INLET has been developed for the inviscid flow in rectangular, supersonic, external-compression inlets. VU-INLET solves for the flow conditions from free stream, through the supersonic compression ramps, across the terminal normal shock region and the subsonic diffuser to the engine face. It calculates the shock locations, the capture streamtube, and the additive drag of the inlet. The inlet geometry can be modified using a graphical user interface and the new flow conditions recalculated interactively. Free stream conditions and engine airflow can also be interactively varied and off-design performance evaluated. Flow results from VU-INLET can be saved to a file for a permanent record, and a series of help screens make the simulator easy to learn and use. This paper will detail the underlying assumptions of the models and the numerical methods used in the simulator.

\section{INTRODUCTION}

The design of high speed inlets is a complex timeconsuming process. The first problem facing the high speed inlet designer is slowing the supersonic external flow down to subsonic speeds before going into the engine. Modern high speed inlets typically employ a series of compression ramps to shock

\footnotetext{
- Senior Research Engineer, Member ALAA

${ }^{\circ}$ Copyright c 1994 by the American Institute of Aeronautics and Astronautics, Inc. No copyright is asserted in the United States under Title 17, U.S. Code. The U.S. Government has a royalty-free license to exercise all rights under the copyright claimed herein for Governmental purposes. All other rights are reserved by the copyright owner.
}

the flow down to subsonic conditions, Refs. 1-3. Because the flow across each shock wave is nonisentropic, there are total pressure losses in the compression process. The total pressure recovery, which is the ratio of the engine face total pressure to free stream total pressure, is one measure of the performance of an inlet. To maximize the inlet recovery, the inlet designer must properly choose the number of compression ramps and the amount of compression along each ramp for various flight conditions. But, as the flow is compressed through the shock waves, it is turned parallel to the ramps creating a new problem; some of the flow may be turned outside of the inlet cowl and be spilled around the inlet. The spillage of flow creates a drag on the aircraft which must be minimized by the inlet designer. A third consideration for the designer is that while a design is usually optimized at certain critical flight conditions, the inlet must continue to operate effectively at off-design conditions. To efficiently operate over a large flight envelope the inlet often employs variable geometry; the compression ramps are hinged and their deflection scheduled as a function of flight conditions. Auxiliary systems such as boundary layer bleed or engine bypass are also included to insure stable inlet operation. A fourth possible inlet problem involves the distribution of flow at the engine face. If the distortion of the flow is too high, either radially or circumferentially, the first stage compressor may surge or stall. And finally aircraft integration problems and low radar cross-sections often impose additional constraints on the inlet design.

During the preliminary design phase, the recovery, drag and off-design operation need to be evaluated for many different geometric configurations. 
The preliminary analysis is usually done assuming one or two dimensional flow and neglecting viscous effects. The pressure recovery for a chosen geometry can be calculated using compressible flow equations given in Refs. 4 and 5. For a given ramp angle, upstream Mach number and ratio of specific heats, the total pressure loss and downstream Mach number are determined. Using this new Mach number as the input to the next ramp, the process can be repeated for a given number of ramps up to and including the terminal normal shock. The inlet recovery is then the product of the recoveries across all the shocks and the engine face recovery is the product of the inlet recovery and the total pressure ratio of the subsonic diffuser. The additive drag of the inlet can be determined by integrating the static pressure ratio along the capture streamtube. The process of calculating the recovery and the drag must be done for each selected geometry condition and free stream condition.

In the past, inlet designers relied on experience, tables, and charts of flow conditions for a wide range of parameters to complete a preliminary design. The generation of the tables and charts was aided by the advent of high speed mainframe computers, but the analysis of this data was time consuming and expensive. Recently, the computing speed and memory capacity of desk top workstations has surpassed that of the older mainframes. In addition, the development of graphical user interfaces (GUI) has provided the researcher with a powerful tool for visualizing and interacting with the computations. The inlet simulator presented here is a first attempt to bring the power of the workstation and the GUI to bear on the problem of high speed inlet design. The resulting tool can be used interactively; the designer can see the result of changes to a configuration instantly and the total design time can be dramatically cut.

\section{ANALYSIS}

For the purpose of analysis, the inlet is divided into three parts. The supersonic part includes the compression ramps and the effects of free stream angle of attack and Mach number. The transonic part includes the terminal normal shock and the region in the vicinity of the cowl lip. The subsonic part includes the region from the cowl lip to the engine face. We will now consider the analysis of each of these regions separately.

\section{Supersonic Compression Ramps}

Along the compression ramps, the designer must determine the oblique shock wave angle, the total pressure ratio, the Mach number change, and the static pressure change across the shock. For very high speed inlets, the static temperature change across the shock can also be important and it is calculated and provided here. For a given Mach number, increasing the ramp angle will increase the shock angle, decrease the downstream Mach number, increase the static pressure and temperature ratios and decrease the total pressure ratio. Above a certain ramp angle the shock wave is no longer oblique but becomes normal and detached and the downstream flow is subsonic. It is necessary for the inlet designer to check and avoid this condition due to the high recovery losses associated with normal shock waves. The appropriate inviscid, compressible flow equations for the compression ramps are given in Ref. 5 as:

$$
\begin{aligned}
\cot \delta & =\tan \theta\left[\frac{(\gamma+1) M^{2}}{2\left(M^{2} \sin ^{2} \theta-1\right)}-1\right] \\
\xi & =\frac{p_{2}}{p_{1}}=\frac{2 \gamma M^{2} \sin ^{2} \theta-(\gamma-1)}{(\gamma+1)} \\
M_{2}{ }^{2} & =\frac{M^{2}[(\gamma+1) \xi+(\gamma-1)]-2\left(\xi^{2}-1\right)}{\xi[(\gamma-1) \xi+(\gamma+1)]}(3) \\
\frac{T_{2}}{T_{1}} & =\xi \frac{(\gamma-1) \xi+(\gamma+1)}{(\gamma+1) \xi+(\gamma-1)} \\
\frac{p t_{2}}{p t_{1}} & =\left[\frac{(\gamma+1) \xi+(\gamma-1)}{(\gamma-1) \xi+(\gamma+1)}\right]^{\frac{\gamma}{\gamma-1}} \xi^{\frac{-1}{\gamma-1}}
\end{aligned}
$$

where $M$ is the upstream Mach number, $M_{2}$ is the downstream Mach number, $\delta$ is the ramp angle, $\theta$ is the shock angle, $\gamma$ is the ratio of specific heats, $p$ is the static pressure, $T$ is the static temperature, and $p t$ is the total pressure, with the " 1 " conditions upstream of the shock and the " $2^{n}$ conditions downstream. Eq. (1) is solved iteratively for the shock angle as a function of the known ramp angle. Knowing the shock angle, Eqs. (2-5) can be easily solved for all the flow conditions across the shock. To determine the maximum ramp angle for which 
the shock wave remains oblique and attached, the following quadratic equation (6) is solved for the value of $\theta_{\max }$. The corresponding maximum ramp angle can then be determined from Eq. (1).

$$
\begin{array}{r}
2 \gamma M^{4} \sin ^{4} \theta_{\max } \\
-\left[(\gamma+1) M^{4}-4 M^{2}\right] \sin ^{2} \theta_{\max } \\
-(\gamma+1) M^{2}+2=0
\end{array}
$$

For multiple ramp inlets, the design procedure is to use the given free stream Mach number and first ramp deflection angle to generate all of the above quantities along the first ramp. The downstream Mach number and the second ramp angle then become the inputs for the second ramp conditions, and so on along all the ramps. If at any time the chosen ramp angle exceeds the shock detachment ramp angle, one must proceed to the terminal shock equations and compute the flow across the detached normal shock. For the first ramp, one must also include the effect of the entire inlet being at some angle of attack. This will increase the effective first ramp angle to be the physical ramp angle plus the angle of attack. The shock wave angle must likewise be adjusted although succeeding ramps are not effected.

It is possible, though not desirable in inlets, for the ramp deflection angle to be negative. In this situation, a compression shock wave is not generated; instead, a centered Prandtl-Meyer expansion is generated and the flow is accelerated. For thoroughness, and to provide for later extensions of the simulator to include mixed compression inlets, we have included the possibility of expansion flows in this simulator. The procedure is to use Eq. (7) to calculate the Prandtl-Meyer angle, as given in Ref. 6 , for the upstream Mach number.

$$
\begin{gathered}
\nu=\sqrt{\frac{\gamma+1}{\gamma-1}} \tan ^{-1} \sqrt{\frac{(\gamma-1)\left(M^{2}-1\right)}{\gamma+1}} \\
-\tan ^{-1} \sqrt{M^{2}-1}
\end{gathered}
$$

The ramp deflection angle is then added to the Prandtl-Meyer angle to give a new downstream value of the Prandtl-Meyer angle.

$$
\nu_{2}=\nu_{1}+\delta
$$

Iteratively solving Eq. (7), one can then determine the downstream Mach number from the new value of the Prandtl-Meyer angle. Since the expansion is isentropic, the total pressure ratio is one and the downstream flow conditions can then be determined by the isentropic relations:

$$
\begin{aligned}
& \frac{T_{2}}{T_{1}}=\frac{\left(1+\frac{\gamma-1}{2} M_{1}^{2}\right)}{\left(1+\frac{\gamma-1}{2} M_{2}^{2}\right)} \\
& \frac{p_{2}}{p_{1}}=\frac{\left(1+\frac{\gamma-1}{2} M_{1}^{2}\right)^{\frac{\gamma}{\gamma-1}}}{\left(1+\frac{\gamma-1}{2} M_{2}^{2}\right)^{\frac{\gamma}{\gamma-1}}}
\end{aligned}
$$

\section{Terminal Shock Region}

The terminal normal shock is the most crucial point in an external-compression inlet design because most of the recovery loss occurs there. At this location the designer must determine the Mach number downstream of the normal shock, the total pressure loss, the static pressure and temperature change, and the location of the shock relative to the cowl lip. The equations governing the flow across normal shocks are similar to those for the oblique shock and are given in Ref. 5 as:

$$
\begin{aligned}
\xi & =\frac{p_{2}}{p_{1}}=\frac{2 \gamma M^{2}-(\gamma-1)}{(\gamma+1)} \\
M_{2}{ }^{2} & =\frac{(\gamma-1) \xi+(\gamma+1)}{2 \gamma \xi}
\end{aligned}
$$

Solving Eq.(11) for $\xi$, Eqs. (4-5) can be used to determine the static temperature and total pressure ratios across the normal shock. Eq. (12) is solved for the Mach number which is then used to determine the corrected airflow through the duct as described below.

For any compressible flow the corrected airflow per unit area can be determined from the following equation which is derived from the continuity equation:

$$
\frac{w \sqrt{\theta_{t}}}{\delta_{t} A}=g \sqrt{\frac{\gamma}{R}} \frac{p_{0}}{\sqrt{T_{0}}} M\left[1+\frac{\gamma-1}{2} M^{2}\right]^{\frac{-(\gamma+2)}{2(\gamma-1)}}
$$

where $\theta_{t}$ is the ratio of total temperature to the reference total temperature $T_{0}, \delta_{t}$ is the ratio of the total pressure to the reference total pressure $p_{0}, g$ is the gravitational constant, $R$ is the gas constant, and $w$ is the airflow. Since the reference conditions are fixed throughout the inlet, the right hand side 
varies only with Mach number. Using the Mach number downstream of the terminal shock and the geometric area at the inlet lip, the maximum corrected airflow through the inlet is determined.

As engine corrected airflow is reduced, the difference between the maximum corrected airflow and the engine corrected airflow is spilled over the cowl of the inlet. To accommodate the spillage, the normal shock moves upstream. There have been a number of models proposed to determine the amount of the shock displacement, Refs. 3 and 7. A slightly different model is employed here which assumes that the spilled airflow is accelerated around the cowl lip to supersonic conditions. Since one knows the amount of the spilled airflow, Eq. (13) can be used with Mach number equal to one to give the airflow per unit area (or length in this two-dimensional simulation). Dividing the spilled airflow by the airflow per unit length gives the length of the sonic line of the spilled airflow. It is then assumed that the sonic line is straight and that it begins on the cowl highlight and runs to the normal shock, parallel to the last ramp. Fig. 1 shows a schematic of these conditions. A comparison of this model has been made with the model in Ref. 3 and is shown in Fig. 2. The new simulator was run in a pitot inlet mode at the specified conditions and the results are shown as filled circles on the graph. In Ref. 3, Seddon conjectures that a square inlet should have a standoff not greatly different than an axisymmetric inlet; results of the new model fall right along the axisymmetric inlet curve.

Having determined the shock angles and flow conditions along each ramp, the additive drag and the mass flow ratio can be calculated. The maximum airflow into the inlet occurs when the terminal shock sits on the cowl lip. Figure 3 shows the construction of the maximum airflow capture streamtube and mass flow ratio. Since each of the compression ramps turn the supersonic flow parallel to the ramp, one can begin at the cowl lip and construct a line parallel to the last ramp upstream until it intersects the last oblique shock. Repeating this process from shock to shock forward to the free stream, one can construct the maximum airflow capture streamtube. The vertical distance from this streamtube to the first ramp leading edge divided by the cowl height gives the maximum possible mass flow ratio. For engine airflows less than the maximum, the mass flow ratio is reduced proportionally and the terminal shock moves upstream as previously described. The capture streamtube is then recalculated from free stream to the terminal shock parallel to the ramps. Downstream of the terminal shock, a straight line is drawn to the cowl lip, as shown in Fig. 4. In actuality the streamtube from the terminal shock to the cowl is curved, but the error introduced by assuming a straight line should be small for moderate mass flow ratios. Integrating the static pressure ratio along the streamtube gives the additive drag. For engine airflows less than the maximum, the average of the static pressure immediately downstream of the terminal shock and the static pressure at the cowl lip is assumed to act over the subsonic portion of the capture streamtube. The static pressure downstream of the normal shock is determined by multiplying the static pressure ratios across all the oblique shocks by the pressure ratio across the normal shock given in Eq. (11). As the airflow is decreased, the cowl lip Mach number is decreased as given by Eq. (13). Assuming isentropic flow from the terminal shock to the cowl lip, the static pressure at the cowl lip can be computed using Eq. (10).

\section{Subsonic Diffuser}

A model for a subsonic diffuser has been included in this simulator for the sake of completeness. It is recognized that subsonic inlet design is a complete subject in its own right and its inclusion in this simulator, while admittedly crude, attempts to account for the loss in recovery from the inlet throat to the compressor face. The recovery loss results from boundary layer growth on the walls of the duct, and from separation of the boundary layer in a region of adverse pressure gradient. The magnitude of the loss depends ultimately on the speed of the flow through the duct and on the geometry of the duct. The subsonic diffuser model used here is based on data and equations given in a course on inlet aerodynamics at Wright-Patterson AFB, Ref. 8. The equations, in turn, were based on subsonic inlet studies, Refs. 9 and 10.

The geometry of the duct provides two parameters for the model; the throat to engine area ratio, and the equivalent conical diffuser angle given by the following equation:

$$
\Theta_{d}=2 \tan ^{-1}\left(\frac{h_{e n g}-h_{t h}}{l}\right)
$$


where $h_{\text {eng }}$ is the height of the engine face, $h_{t h}$ is the throat height, and $l$ is the length of the duct from the throat to the engine face. The geometric parameters are used to calculate the recovery loss coefficient given by the following equations:

$$
\begin{aligned}
K_{n}= & K_{1}\left(1-\frac{h_{t h}}{h_{\text {eng }}}\right)^{2}+ \\
& .02 K_{2}\left[1-\left(\frac{h_{t h}}{h_{\text {eng }}}\right)^{2}\right] \\
K_{1}= & 0.011 \Theta_{d} \quad \text { for } \Theta_{d}<20 \\
= & 0.033 \Theta_{d}-.44 \quad \text { for } \Theta_{d}>20 \\
K_{2}= & \frac{0.1412}{\tan \left(\frac{\Theta_{d}}{2}\right)}
\end{aligned}
$$

The $K_{1}$ and $K_{2}$ coefficients represent the effects of flow separations and boundary layer growth respectively. These equations were derived from curve fits of experimental data for representative subsonic ducts. The final duct recovery then becomes:

$$
\frac{p t_{2}}{p t_{1}}=1.0-.5 M_{t h} K_{n}
$$

where $M_{t h}$ is the throat Mach number derived from Eq.(13) for the particular engine corrected airflow and throat area.

\section{DESCRIPTION OF SIMULATOR}

Figures 5-9 are screen dumps from Version 2.0 of VU-INLET and are included here to illustrate some of the features available in the simulator. Considering Fig. 5, the simulator is divided into three main sections; a view screen at the top, the input box in the lower left, and the output box in the lower right. The view screen shows a schematic drawing of the inlet geometry, the oblique and and normal shock waves, the capture streamtube, numerical labels on the flow zones between the shock waves, and an arrow indicating the free stream flow direction. On the workstation these features are all color-coded, but are presented here in black and white. Around the view window are some buttons to invoke the help and output screens and to vary the display in the view window. Fig. 6 shows the results of pushing the "Filled/Lines" button to the right and below the view screen, while Fig. 8 shows the display in black on white from the "Color/B and W" button to left and below the view screen. The black and white presentation is very useful for technical reports. Pushing the "Help" button will invoke an additional view window as shown in Fig. 9. The user can then choose a topic of interest using the buttons on the right and scroll through the narrative to help solve immediate problems. Returning to Fig. 5, the three sliders located around the view window control the location and size of the display.

The input box to the left and below the view screen controls the geometry and flow input variables. The user can fix the flow conditions and vary the geometry, or fix the geometry and vary the flow conditions by selecting the appropriate button at the top of the box. The darkened window in the button indicates the choice and a separate interaction screen appears in the box. Figs. 5 and 7 show the geometry screen which is divided into separate sections for the external ramps, the cowl lip, the shoulder, and the engine face. The user can input data either by typing into the input windows or by moving the sliders using a mouse; the choice is made by pushing the "Slider/Enter" button which sits between each of the input windows and the sliders as noted in Figs. 5 and 7. As the geometry is changed from that in Fig. 5 to that in Fig. 7, the simulator recalculates all of the fiow variables, displays the current output parameters, and changes the geometry and the shocks in the view window. Figs 6 and 8 show the analysis screen in the input box. This screen contains buttons to specify what type of analysis is to be performed; either external or mixed compression, with or without drag calculation. Free stream and engine face conditions can be specified as before. The mixed compression option with engine bypass is not yet available.

The output box to the right of the input box controls the presentation of numerical results to the user. The box contains a fixed screen at the bottom showing drag, Mach number and recovery through the inlet, and optional screens at the top. The optional screens can display either a single flow variable through all of the flow zones as in Figs. 5,7, and 8 or all of the flow variables within a single zone as in Fig 6. The data is displayed both numerically and graphically using variable bar charts; as conditions change the length of the bar changes 
appropriately. Comparing Figs. 5 and 7 , the user can pick which variable to display through the inlet and the reference conditions. The previous zone reference will display the ratio of variables from zone to zone, while the free stream reference will display differences in the flow variable.

VU-INLET has been designed to be highly interactive with the user. To assist the user in the operation of the program, a series of help screens are available. An example of this capability is shown in Fig. 9. The user can also save design conditions to a file for printing or archiving by pushing the output button. This may be done as many times as desired during a session with the simulator.

\section{RESULTS}

The results presented in Figs. 5-8 are examples of the types of problems which can be studied using VU-INLET. While these figures are presented here as screen dumps, the real power of the simulator is its ability to recalculate and redisplay the results almost instantly. The geometry and flow conditions can be immediately varied by the user to optimize parameters of interest to the user. It is the interaction of the user with the tool which will produce a good design; the package alone will not inversely design an inlet.

Fig. 5 show a typical two ramp inlet at Mach 2.0, zero angle of attack. The first shock lays far off the cowl lip resulting in a low mass flow ratio (.807). The results shown in the output box have been checked versus Ref. 5 to insure proper coding. As the engine airflow is reduced to 77 per cent of the maximum, the simulator gives the results shown in Fig. 6. The normal shock has moved upstream, the capture streamline has moved closer to the ramp surface and the additive drag has increased substantially. The throat Mach number has decreased and the subsonic diffuser recovery has increased, resulting in a higher recovery at the engine face. The supersonic compressor has remained unchanged and the output box now shows conditions along the second ramp. Again all the ramp conditions agree exactly with the results from Ref. 5 .

Fig. 7 shows a three ramp inlet with the dummy engine face removed and the drag calculation disabled. Static pressure is displayed in the output window and is seen to steadily increase along the compression ramps. The additional ramp produces a. larger recovery and higher Mach number aft of the normal shock than in Fig. 5, although the recovery of the subsonic duct is lower due to the higher throat Mach number. Fig. 8 shows the same geometric conditions as Fig. 7, but the free stream now approaches at 4.0 degrees angle of attack. The initial ramp is then inclined 14.0 degrees to the free stream, producing a stronger shock, higher static pressure, lower total pressure and lower Mach number along the first ramp. As the flow approaches the third ramp, the oblique shock can no longer remain attached and a normal shock is produced. A flag in the output box tells the user that the shock is detached, the number of flow zones is reduced to three and the calculation of the subsonic duct is disabled because of uncertainties associated with the large region of subsonic external flow.

\section{SUMMARY}

A workstation-based, highly interactive design tool for supersonic, rectangular, external compression inlets has been developed. The underlying assumptions and equations which form the basis for this tool have been presented in this paper as well as several examples of the results from the simulator. This tool should greatly speed up the preliminary design process for high speed inlets. It can also be used as an educational tool for graduate aerodynamicists because it includes most of the physical processes which occur in high speed inlets. The model does neglect the effects of boundary layers which can and have caused big problems for inlets, and the geometry is only two dimensional. However, the tool can be used effectively for preliminary design and screening. VU-INLET is now being upgraded to solve for the flow in mixed compression inlets and there are plans to expand the analysis to the method of characteristics to solve for axisymmetric inlets and distributed compression surfaces.

The use of highly interactive graphics and graphical user interfaces employed in VU-INLET has already led to the development of an undergraduate educational tool which can assist in teaching basic compressible flow results from NACA-1135, Ref. 11. Many of the features and assumptions which went into the supersonic compressor of the inlet simulator were directly applicable to the educational tool. 


\section{ACKNOWLEDGEMENTS}

The current simulator uses the FORMS library for graphical user interfaces developed by Mark H. Overmars, Department of Computer Science, Utrecht University, The Netherlands for Silicon Graphics workstations. Some modifications to this library have been made to allow the package to also be used on IBM Risc 6000 machines. All of this software is public domain and may be copied and used for non-commercial products, but not resold. Copies of the source are available from the author at the NASA Lewis Research Center.

\section{REFERENCES}

1. Seddon, J., "Intake Aerodynamics", von Karman Institute for Fluid Dynamics Lecture Series 1988-04, February, 1988.

2. Schmidt, W. and Bradley, R.G, "Air Intakes for High Speed Vehicles", Agard Advisory Report 270 - Working Group 13, September, 1991.

3. Seddon, J., and Goldsmith, E.L., Intake Aerodynamics, AlAA Education Series, New York, 1985.

4. Shapiro, A.H., The Dynamics and Thermodynamics of Compressible Flow, Ronald Press, New York, 1953.

5. Ames Research Staff, "Equations, Tables and Charts for Compressible Flow", NACA Report $1135,1953$.

6. Liepman, H.W. and Roshko, A., Elements of Gasdynamics, Wiley and Sons, London, 1957.

7. Moeckel, W.E., "Approximate method for predicting form and location of detached shock waves ahead of plane or axially symmetric bodies", NACA TN 1921, 1949.

8. Throndson, L.W., "Internal Aerodynamic Lecture Course", Wright-Patterson, Air Force Base, August, 1967.

9. SAE Committee A-9, "Aero-Space Applied Thermodynamics Manual", Society of Automotive Engineers, Inc., February, 1960.

10. Henry, J.R., Wood, C.C., and Wilbur, S.W., "Summary of Subsonic Diffuser Data", NACA Report No. RML 56F05, October, 1956.

11. Benson, T.J., "Interactive Educational Tools for Compressible Aerodynamics" AIAA 94-3117, to be presented June, 1994. 


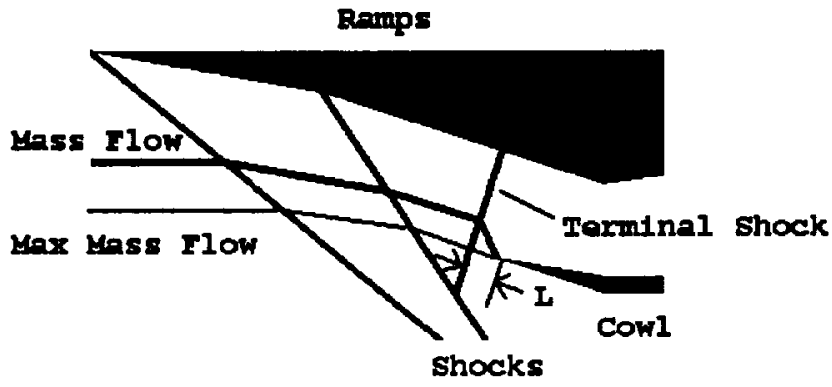

Fig. 1 shock standoff geometry.

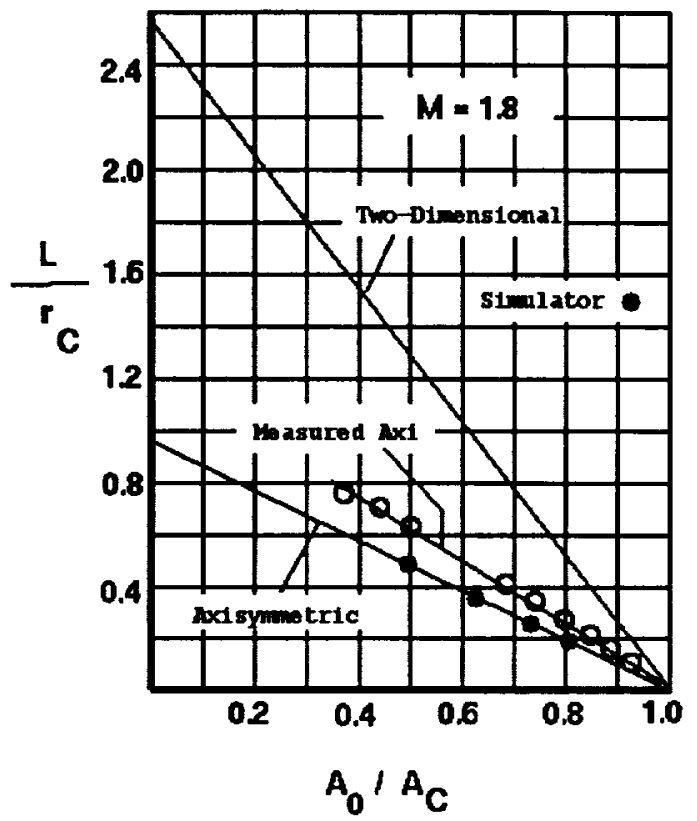

F1g. 2 Comparison of shock standoff models.

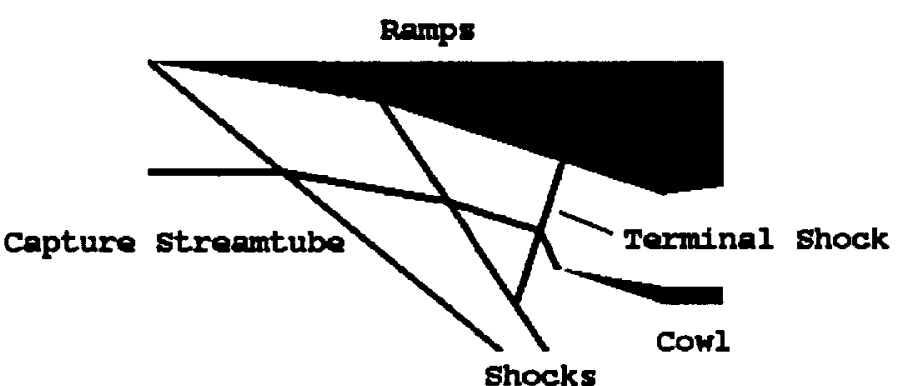

Fig. 4 subsonic stroamtube.

Fig. 3 Capture streamtube construction. 


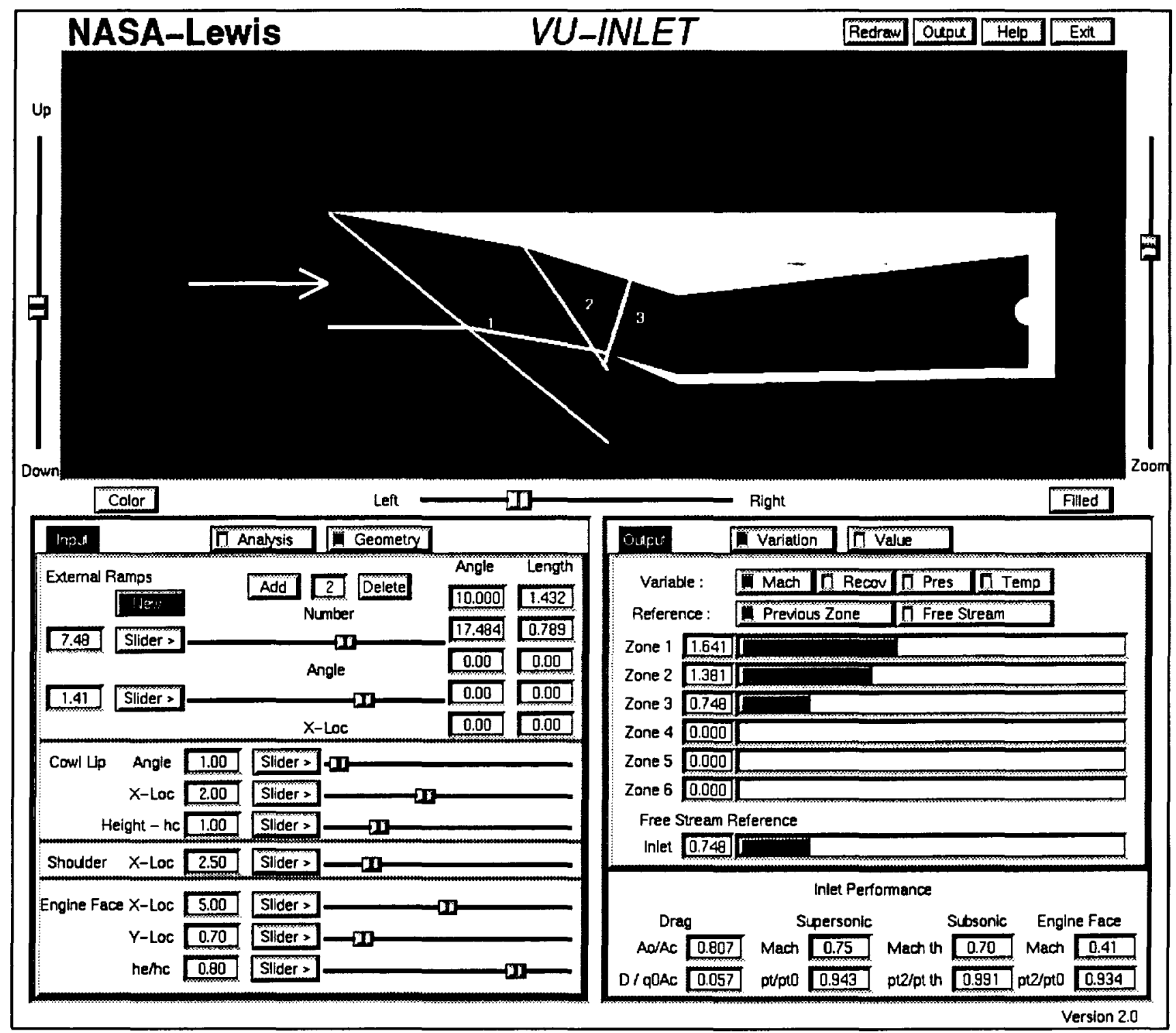

Fig. 5 Simulator screen dump. 


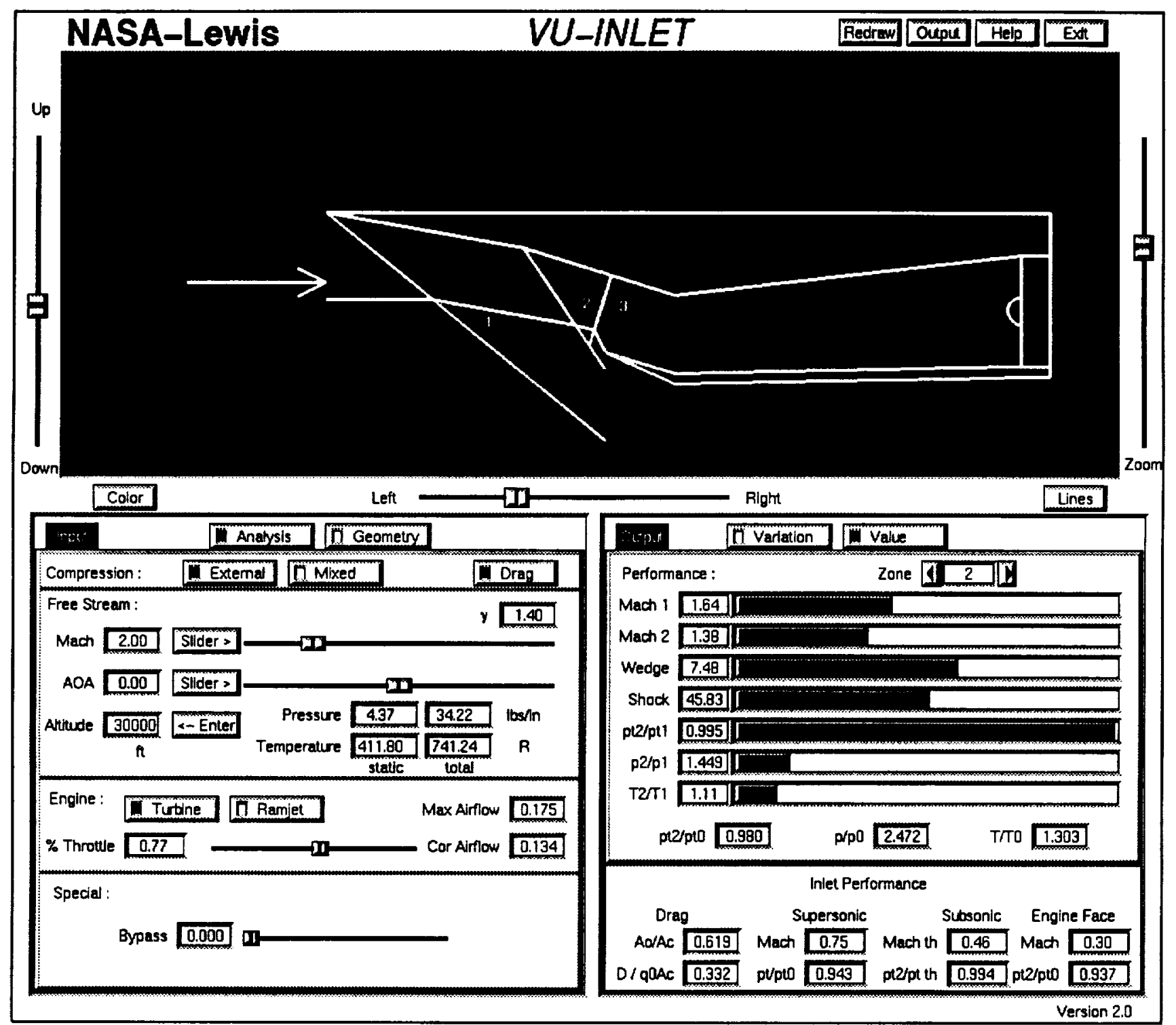

Fig. 6 Reduced airflow. 


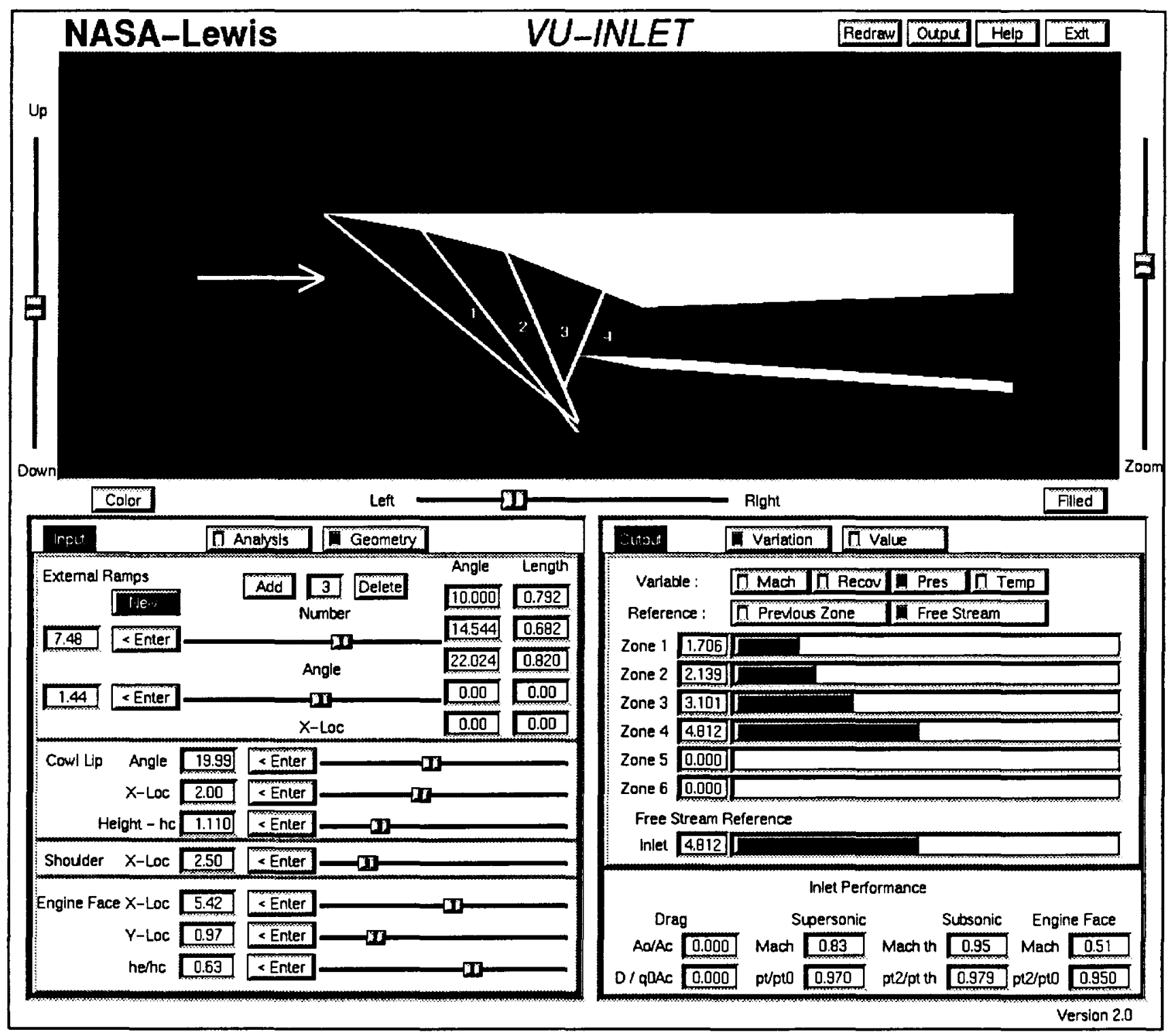

Fig. 7 Three ramp inlet. 


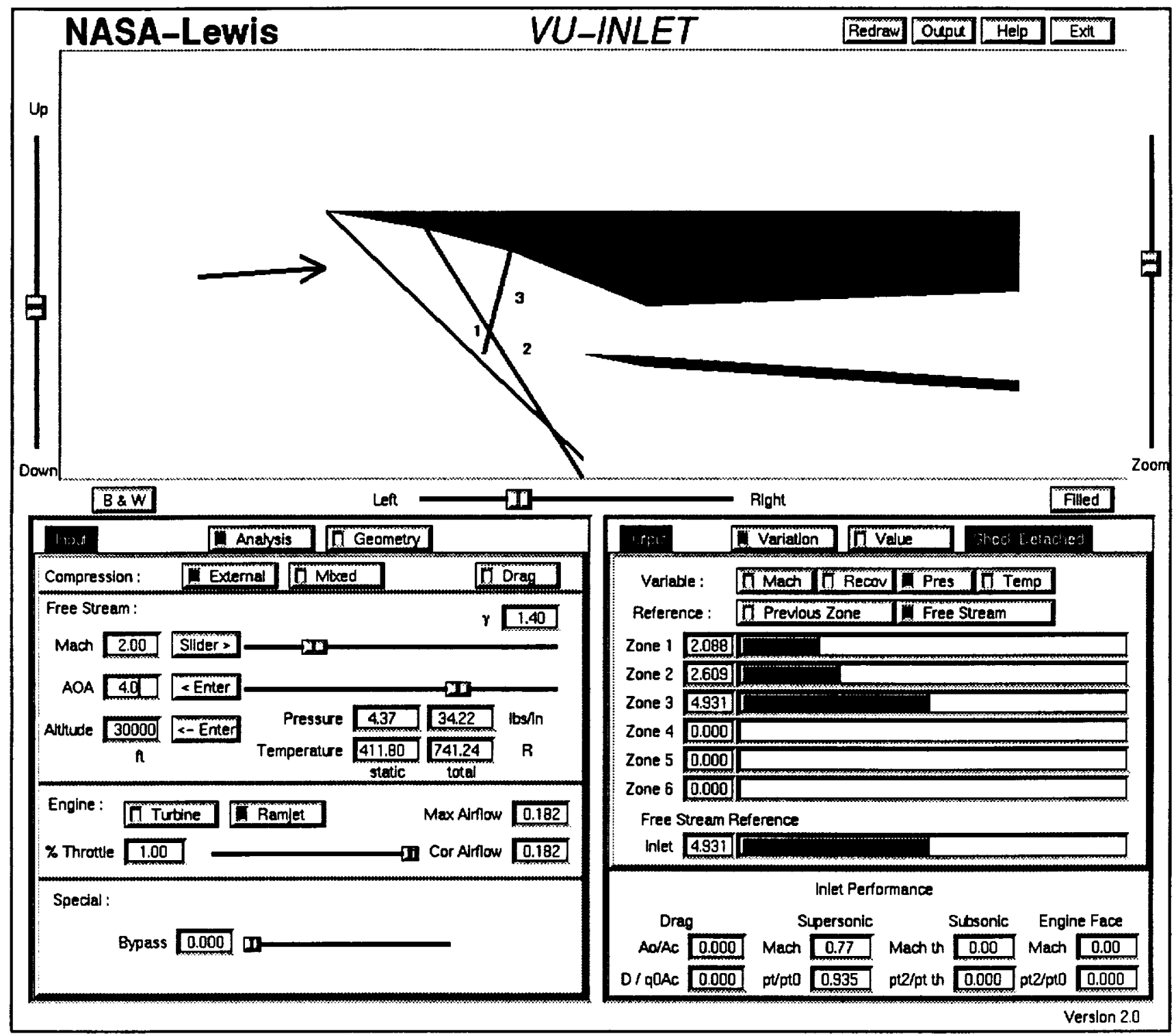

Fig. 8 Detached shock wave. 


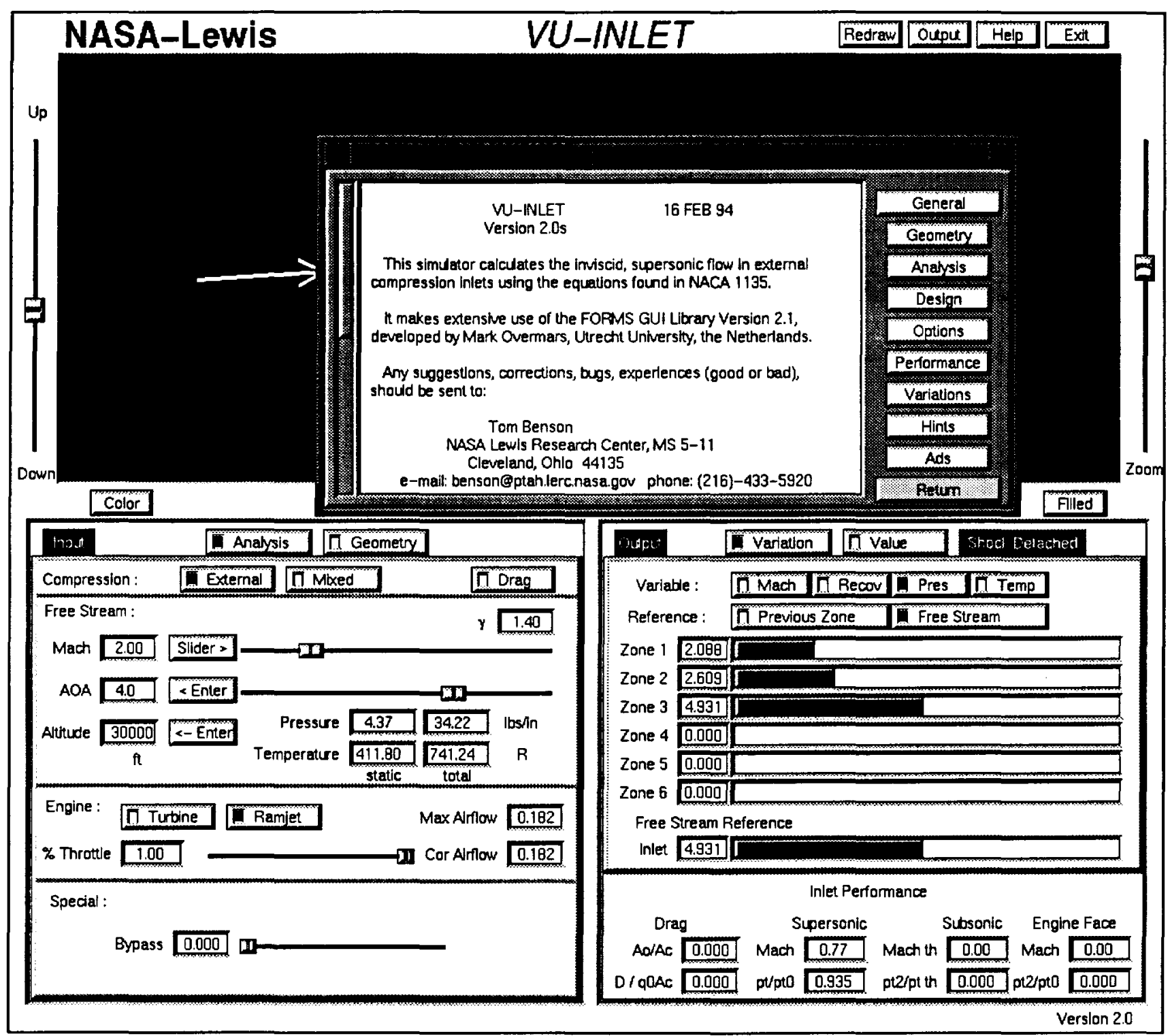

Fig. 9 Help screen. 
Public reporting burden for this collection of information is estimated to average 1 hour per response, including the time for reviewing instructions, searching existing data sources, gathering and maintaining the dala needed, and completing and reviewing the collection of information. Send comments regarding this burden estimate or any other aspoct of this coliection of information, including suggestions tor reducing this burden, to Washington Headquarters Services, Directorate for Information Operations and Reports, 1215 Jether
Davis Highway. Suite 1204. Artington, VA 22202-4302, and to the Office of Management and Budget. Paperwork Peduction Project (0704-0188), Washington, DC 20503.

\begin{tabular}{|l|l|l|}
\hline 1. AGENCY USE ONLY (Leave blank) & $\begin{array}{c}\text { 2. REPORT DATE } \\
\text { May } 1994\end{array}$ & $\begin{array}{r}\text { 3. REPORT TYPE AND DATES COVERED } \\
\text { Technical Memorandum }\end{array}$ \\
\hline
\end{tabular}

\section{TITLE AND SUBTITLE}

An Interactive, Design and Educational Tool for Supersonic ExternalCompression Inlets

6. AUTHOR(S)

Thomas J. Benson

\section{PERFORMING ORGANIZATION NAME(S) AND ADDRESS(ES)}

National Aeronautics and Space Administration

Lewis Research Center

Cleveland, Ohio 44135-3191

9. SPONSORING/MONITORING AGENCY NAME(S) AND ADDRESS(ES)

National Aeronautics and Space Administration

Washington, D.C. 20546-0001
5. FUNDING NUMBERS

WU-505-62-52
8. PERFORMING ORGANIZATION REPORT NUMBER

E-8841

11. SUPPLEMENTARY NOTES

Prepared for the 30th Joint Propulsion Conference cosponsored by the AIAA, ASME, SAE, and ASEE, Indianapolis, Indiana, June 27-29, 1994. Thomas J. Benson, NASA Lewis Research Center. Responsible person, Thomas J. Benson, organization code 2670, (216) 433-5920.

12a. DISTRIBUTION/AVAILABILITY STATEMENT

12b. DISTAIBUTION CODE

Unclassified - Unlimited

Subject Category 61

10. SPONSORING/MONITORING AGENCY REPORT NUMBER

NASA TM-106581

13. ABSTRACT (Maximum 200 words)

A workstation-based interactive design tool called VU-INLET has been developed for the inviscid flow in rectangular, supersonic, external-compression inlets. VU-INLET solves for the flow conditions from free stream, through the supersonic compression ramps, across the terminal normal shock region and the subsonic diffuser to the engine face. It calculates the shock locations, the capture streamtube, and the additive drag of the inlet. The inlet geometry can be modified using a graphical user interface and the new flow conditions recalculated interactively. Free stream conditions and engine airflow can also be interactively varied and off-design performance evaluated. Flow results from VU-INLET can be saved to a file for a permanent record, and a series of help screens make the simulator easy to learn and use. This paper will detail the underlying assumptions of the models and the numerical methods used in the simulator.

\begin{tabular}{|c|c|c|c|}
\hline & \multirow{2}{*}{$\begin{array}{l}\text { 15. NUMBER OF PAGES } \\
15 \\
\text { 16. PRICE CODE } \\
\text { A03 }\end{array}$} \\
\hline & & $\begin{array}{l}\text { 14. SUBJECT TERMS } \\
\text { Supersonic; Inlet; Design }\end{array}$ & \\
\hline
\end{tabular}

